\title{
Resonancia magnética del bracket longitudinal epifisario pre-osificado
}

\section{Magnetic Resonance Imaging of the Pre-ossified Epiphyseal Longitudinal Bracket}

\author{
Javier Masquijo ${ }^{1}$ Rodrigo $\operatorname{Re}^{2}$ \\ ${ }^{1}$ Departamento de Ortopedia y Traumatología Infantil, Sanatorio \\ Allende, Córdoba, Argentina \\ 2 Departamento de Diagnóstico por Imágenes, Sanatorio Allende, \\ Córdoba, Argentina
}

Rev Argent Radiol 2019;83:23-25.

Estimados editores,

El bracket longitudinal epifisario ("hueso delta"), es un defecto raro de osificación de los huesos largos de la mano y el pie. Esa deformidad contiene un centro de osificación secundario anormal en forma de $\mathrm{C}$ que une la diáfisis y la metáfisis. Eso conduce a un acortamiento progresivo y deformidad angular del hueso afectado. ${ }^{1-4}$

La historia natural consta de cuatro etapas: I) Preosificada, II) Osificación proximal y distal al bracket, III) Osificación completa y IV) Cierre fisario (-Fig. 1). ${ }^{4}$ En la evaluación de las etapas iniciales, la radiografía tiene un rol limitado, ya que no permite identificar la lesión cuando ella no se encuentra osificada. La resonancia magnética (RM), ha evolucionado enormemente en los últimos años, aumentado sus indicaciones clínicas. Debido a que es un estudio no

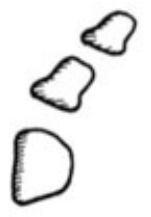

I

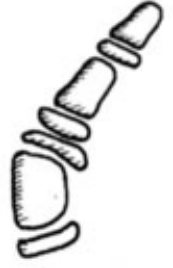

II

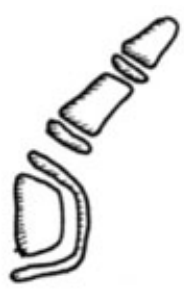

III

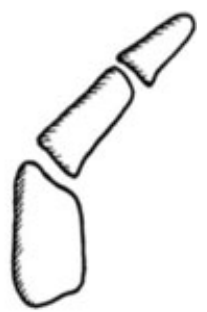

IV
Fig. 1 Etapas de la historia natural del bracket longitudinal epifisario. I) Pre-osificada, II) Osificación proximal y distal al bracket, III) Osificación completa y IV) Cierre fisario. Modificado de Shea KG, Mubarak SJ, Alamin T. Preossified longitudinal epiphyseal bracket of the foot: treatment by partial bracket excision before ossification. J Pediatr Orthop. 2001 May-Jun;21(3):360-5. received April 19, 2018 published online October 11, 2018 October 23, 2017 accepted
Address for correspondence Javier Masquljo, MD, Departamento de Ortopedia y Traumatología Infantil, Sanatorio Allende, Sanatorio Allende, Av. H. Irigoyen 384, Córdoba, Argentina (e-mail: jmasquijo@gmail.com).

invasivo, de alto contraste y capacidad multiplanar, se ha convertido en una modalidad diagnóstica esencial para evaluar cartílago y hueso. En este reporte, describimos los hallazgos por RM de dos pacientes con diagnóstico de bracket longitudinal epifisario pre-osificado en manos y pies.

Presentamos el caso de una paciente de seis meses de edad, sana y sin antecedentes patológicos de relevancia, que fue traída a la consulta por sus padres por presentar dedos supernumerarios en ambos pies. Al examinarla se confirmó el diagnóstico de polidactilia pre-axial, bilateral (duplicación del hallux), sin otras malformaciones asociadas. El diagnóstico de bracket longitudinal epifisario se sospechó en las radiografías y se confirmó mediante RM (-Fig. 2 ).

El otro caso corresponde a un paciente de 3 años de edad que fue traído a la consulta por sus padres por deformidad del quinto dedo de ambas manos. Como antecedente familiar, el padre y el hermano presentaban una deformidad similar pero más leve. Al examen físico, presentaba una desviación lateral severa de ambos meñiques (clinodactilia), sin otra deformidad asociada. Inicialmente se solicitaron radiografías, donde se comprobó el grado de angulación interfalángico (-Fig. 3A). Luego se solicitó RM, donde se identificó un bracket longitudinal epifisario bilateral (-Fig. 3B).

El termino bracket longitudinal epifisario (BLE), fue acuñado por Theandery Carstam $^{5}$ para describir una anormalidad del cartílago de crecimiento de huesos tubulares. En lugar de presentar una orientación transversa, la fisis tiende a incurvarse y tomar una forma de $C$ extendiéndose en la metáfisis y diáfisis del hueso afectado. El desarrollo inadecuado del centro de osificación durante el período embrionario o fetal temprano ha sido

\section{Copyright (๑) 2019, Sociedad Argentina de Radiología. Publicado por Thieme Revinter Publicações Ltda., Rio de \\ License terms (ㄷ) (i) $\ominus$ (2)} Janeiro, Brazil. Todos los derechos reservados. 10.1055/s-0038-1656539. ISSN 1852-9992. 

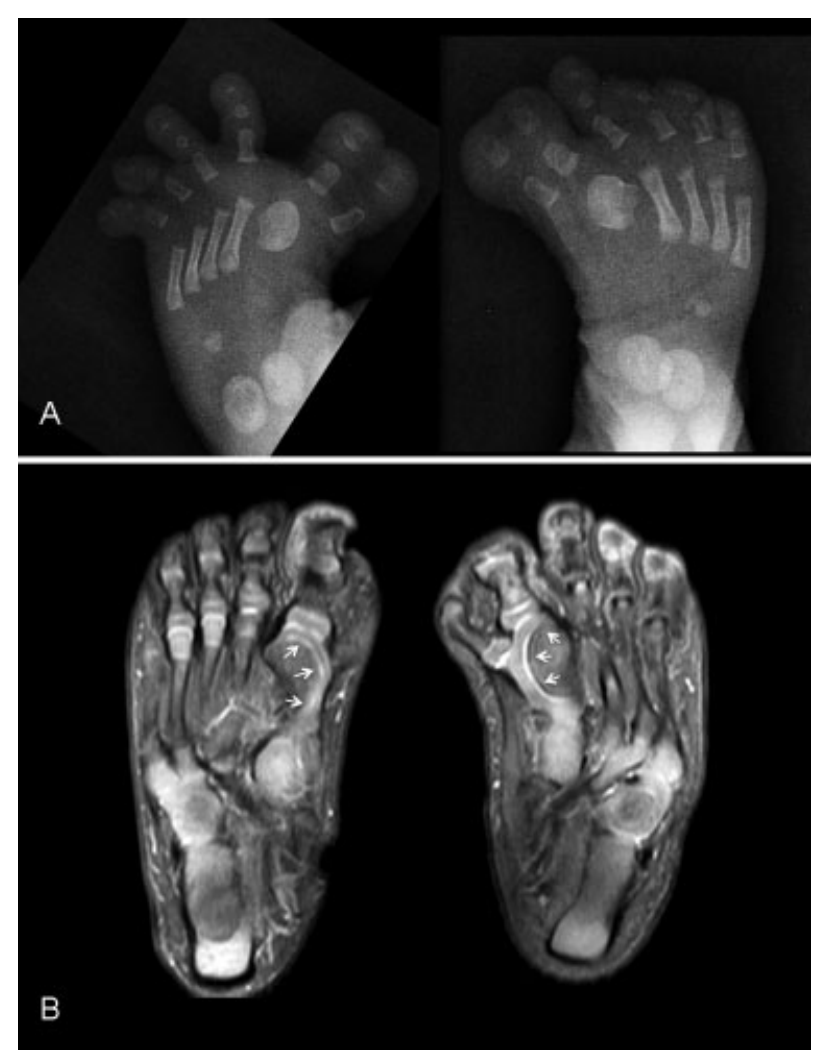

Fig. 2 Caso 1. (A) Radiografía de frente de ambos pies donde puede observarse polidactilia preaxial y deformidad asociada del primer metatarsiano. (B) Resonancia magnética en secuencia STIR (TE: 30/ 3500) donde se objetiva polidactilia con falange adicional que se articula con el metatarsiano del hallux. Sobre la región medial se visualiza además una barra cartilaginosa (flechas) que une la fisis proximal y distal del primer metatarsiano produciendo una deformidad en varo. propuesto como una de las causas que podrían producir el BLE. $^{6}$ Esa patología se ha asociado con otras afecciones tales como hallux varus congénito, polidactilia, síndrome de Rubenstein-Taybi, síndrome de Apert, hemimelia tibial, sindactalia y manos hendidas. ${ }^{2,6}$ En los pacientes con duplicación del hallux (polidactilia preaxial), el BLE tiene una alta frecuencia de presentación. Mosca encontró una incidencia del 34\% de BLE en un grupo de 61 pacientes con polidactilia de pie (comunicación personal).

Históricamente, el tratamiento quirúrgico ha consistido en una osteotomía cuando se alcanza la madurez esquelética. ${ }^{1,7}$ Estudios más recientes proponen realizar la fisiólisis central (resección de la porción central del bracket) previo a la osificación para permitir la corrección progresiva. ${ }^{2,4,8}$ La fisiólisis central es un procedimiento simple que puede reducir o corregir completamente la deformidad. La edad en el momento de la intervención es un factor importante que afecta el grado de corrección, obteniéndose los mejores resultados cuando la cirugía es realizada de manera precoz. Para ello es importante realizar un correcto diagnóstico. La radiografía es el primer estudio que debe solicitarse para evaluar la magnitud de la deformidad. El primer metatarsiano suele presentarse dismórfico. Sin embargo, presenta limitaciones en niños muy pequeños durante la etapa de pre-osificación. Schreck $^{9}$ ha propuesto la utilización de ecografía como complemento diagnóstico. Si bien representa una opción menos costosa, tiene la limitación de requerir un ecografista entrenado en patología músculo-esquelética. La RM tiene un papel importante en la evaluación de los trastornos epifisarios mediante la demostración de estructuras cartilaginosas y óseas con gran detalle sin el
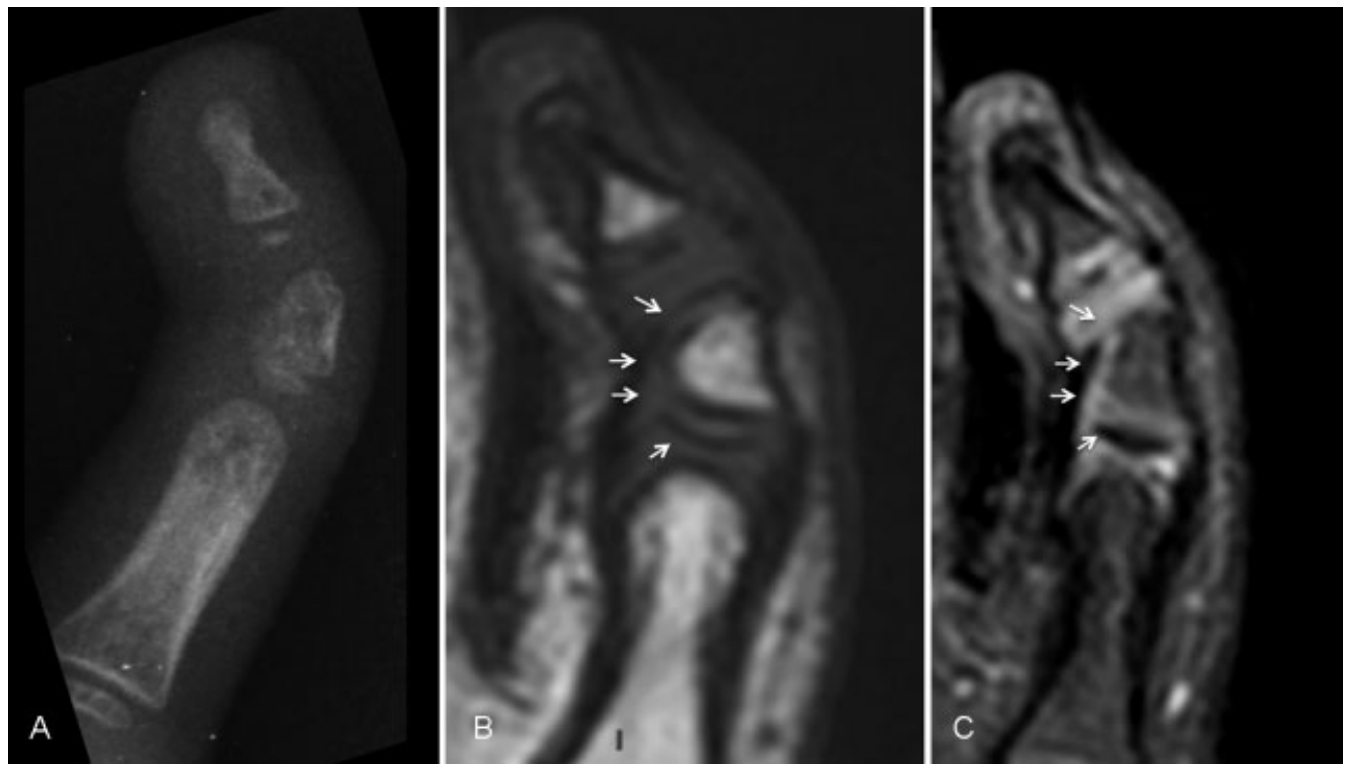

Fig. 3 Caso 2. (A) Radiografía de frente donde puede observarse una deformidad tipo delta en la segunda falange del dedo meñique. (B) Resonancia magnética en secuencia ponderada en T1 (TE:22/TR:440) donde se observa barra hipointensa en la segunda falange del quinto dedo sobre la cara radial que une los cartílagos de crecimiento y deforma la falange, con angulación característica de la falange en Delta (flechas). (C) Resonancia magnética en secuencia STIR (TE:35/TR:1100) donde se visualiza barra hiperintensa en la segunda falange (flechas). 
uso de radiación ionizante. Las características de la intensidad de señal del cartílago en la RM convencional reflejan principalmente la cantidad de agua dentro de la matriz y las células. En las imágenes ponderadas en T1, todo cartílago hialino tiene intensidad de señal intermedia y la zona de calcificación presenta intensidad de señal muy baja. En las imágenes de alta resolución espacial sensibles a los fluidos como T2 y tiempo corto de inversión-recuperación (STIR), el cartílago articular muestra alta intensidad de señal y el cartílago epifisario muestra intensidad de señal muy baja debido a la fuerte unión del agua a las macromoléculas. $^{10}$ La RM nos permitió identificar de manera correcta la patología y realizar una planificación pre-quirúrgica precoz del mismo. Si bien en esos casos las imágenes fueron adquiridas con un resonador $1.5 \mathrm{~T}$, consideramos que un equipo 3.0 T aportaría reducción en el tiempo de adquisición de las imágenes y una mayor caracterización con información más detallada.

\section{Confidencialidad de Los Datos}

Los autores declaran que han seguido los protocolos de su centro de trabajo sobre la publicación de datos de pacientes y que todos los pacientes incluidos en el estudio han recibido información suficiente y han dado su consentimiento informado por escrito.

\section{Conflicto de Intereses}

Los autores del trabajo declaran no tener ningún conflicto de intereses, excepto el Dr. Re que declara como posible conflicto de interés pertenecer al Comité de Redacción de la RAR. Cada autor certifica que no existe una asociación comercial que pueda suscitar un conflicto de intereses en relación con el trabajo remitido.

\section{Bibliografía}

1 Light TR, Ogden JA. The longitudinal epiphyseal bracket: implications for surgical correction. J Pediatr Orthop 1981;1 (03):299-305

2 Mubarak SJ, O'Brien TJ, Davids JR. Metatarsal epiphyseal bracket: treatment by central physiolysis. J Pediatr Orthop 1993;13(01):5-8

3 Sobel E, Levitz S, Cohen R, Giorgini R, Jules KT. Longitudinal epiphyseal bracket: associated foot deformities with implications for treatment. J Am Podiatr Med Assoc 1996;86(04):147-155

4 Shea KG, Mubarak SJ, Alamin T. Preossified longitudinal epiphyseal bracket of the foot: treatment by partial bracket excision before ossification. J Pediatr Orthop 2001;21(03):360-365

5 Carstam N, Theander G. Surgical treatment of clinodactyly caused by longitudinally bracketed diaphysis ("delta phalanx"). Scand J Plast Reconstr Surg 1975;9(03):199-202

6 Ogden JA, Light TR, Conlogue GJ. Correlative roentgenography and morphology of the longitudinal epiphyseal bracket. Skeletal Radiol 1981;6(02):109-117

7 Smith RJ. Osteotomy for "delta-phalanx" deformity. Clin Orthop Relat Res 1977;(123):91-94

8 Vickers D. Clinodactyly of the little finger: a simple operative technique for reversal of the growth abnormality. J Hand Surg [Br] 1987;12(03):335-342

9 Schreck MA. Pediatric longitudinal epiphyseal bracket: Review and case presentation. J Foot Ankle Surg 2006;45(05):342-345

10 Jaimes C, Chauvin NA, Delgado J, Jaramillo D. MR imaging of normal epiphyseal development and common epiphyseal disorders. Radiographics 2014;34(02):449-471 